\title{
ANALISIS KEBUTUHAN UNTUK PENGEMBANGAN MEDIA PEMBELAJARAN IPA BERBASIS MIND MAPPING
}

\author{
I.K. Dadi, I.W. Redhana, P.P. Juniartina \\ Program Studi S1 Pendidikan IPA \\ Universitas Pendidikan Ganesha \\ Singaraja, Indonesia \\ e-mail: i.ketut.dadi@undiksha.ac.id, redhana.undiksha@gmail.com, \\ prima.juniartina@undiksha.ac.id
}

\begin{abstract}
Abstrak
Tujuan penelitian ini adalah melakukan analisis kebutuhan untuk merancang media pembelajaran IPA berbasis mind mapping. Analisis kebutuhan dilakukan melalui studi literatur dan studi lapangan. Studi literatur dilakukan untuk mengumpulkan informasi mengenai konsep materi IPA di kelas VIII semester 2. Hasil analisis konsep pada materi cahaya dan alat optik menunjukan bahwa 44\% konsep abstrak, 52\% konsep konkret, dan 4\% konsep berdasarkan prinsip. Studi lapangan dilakukan untuk mengumpulkan informasi mengenai proses pembelajaran di kelas dan media yang digunakan. Hasil analisis kebutuhan dari 19 orang guru IPA dan 190 orang siswa di Kabupaten Buleleng khususnya di Kecamatan Buleleng dan Kecamatan Sawan menunjukan bahwa 100\% guru menyatakan media pembelajaran IPA berbasis mind mapping itu menarik, 100\% guru menginginkan perlunya dikembangkan media pembelajaran IPA berbasis mind mapping dan $100 \%$ guru menyatakan setuju menggunakan media pembelajaran IPA berbasis mind mapping dalam menjelaskan konsep IPA. Hasil analisis kebutuhan siswa juga mendapatkan hasil yang tidak jauh berbeda dengan hasil analisis kebutuhan guru, 95,3\% siswa menyatakan media pembelajaran IPA berbasis mind mapping itu menarik dan $97,4 \%$ siswa menyatakan setuju menggunakan media pembelajaran IPA berbasis mind mapping pada kegiatan belajar di kelas. Hasil studi literatur dan studi lapangan menunjukkan bahwa perlu dikembangkan media pembelajaran IPA berbasis mind mapping.
\end{abstract}

Kata kunci: analisis kebutuhan, media pembelajaran IPA, mind mapping

\begin{abstract}
The purpose of this study is to conduct a needs analysis to design a mind-based science learning media. Needs analysis is done through literature studies and field studies. Literature study was conducted to gather information about the concept of science material in class VIII semester 2. The results of $c$ oncept analysis on light material and optical devices showed that $44 \%$ abstract concepts, $52 \%$ concrete concepts and $4 \%$ concepts based on principles. Field studies are conducted to collect information about the learning process in the classroom and the media used. The results of the needs analysis of 19 science teachers and 190 students in Buleleng Regency, especially in Buleleng and Sawan Subdistricts shows that $100 \%$ of teachers said mind mapping-based science learning media were interesting, $100 \%$ of teachers wanted the need to develop mind mapping based science learning media. and $100 \%$ of teachers stated that they agreed to use mind-based science learning media in explaining the science concept. The results of student needs analysis also get results that are not much different from the results of the analysis of teacher needs, $95.3 \%$ of students stated mind mapping based science learning media was interesting and $97.4 \%$ of students said they agreed to use mind mapping-based science learning media in learning activities in the classroom. The results of literature studies and field studies show that it is necessary to develop mind mapping based science learning media.
\end{abstract}

Keywords: needs analysis, science learning media, mind mapping 


\section{PENDAHULUAN}

Pendidikan merupakan tolak ukur kemajuan suatu bangsa. Tujuan pendidikan nasional menurut UU nomor 20 Sistem Pendidikan Nasional tahun 2003 adalah mengembangkan potensi peserta didik agar menjadi manusia yang beriman dan bertakwa terhadap Tuhan Yang Maha Esa, berakhlak mulia, sehat, berilmu, cakap, kreatif, mandiri dan menjadi warga yang demokratis serta bertanggung jawab. Peningkatan mutu pendidikan merupakan komitmen untuk meningkatkan mutu sumber daya manusia sebagai modal dasar pembangunan bangsa, agar dapat sejajar dengan Negara-negara lain di dunia (Depdiknas 2004). Peningkatan mutu pendidikan merupakan salah satu usaha untuk mencapai tujuan pendidikan.

Menjawab tuntunan tersebut pemerintah memandang perlu adanya perbaikan dan penyempurnaan kurikulum pendidikan sains karena kurikulum merupakan jantungnya pendidikan (Rosyada, 2004). Perubahan kurikulum pada dasarnya bertujuan untuk menyesuaikan proses pendidikan dengan tuntunan perkembangan zaman serta perubahan ilmu pengetahuan dan teknologi yang dilaksanakan dengan pengembangan kurikulum. Pengembangan kurikulum diarahkan mencapai tujuan tertentu, yang bertitik tolak dari tujuan pendidikan nasional (Hamalik, 2013). Usaha-usaha yang dilakukan pemerintah untuk mencapai tujuan tersebut belum berhasil secara maksimal.

Masalah pendidikan di Indonesia apabila ditinjau dari sisi kualitas sumber daya manusia masih jauh bila dibandingkan dengan Negara-negara lain. Bedasarkan data World Education Ranking yang diterbitkan Organication for Economic Coperation and Development (OECD), dalam organisasi ini menentukan peringkat Negara ditinjau dari segi membaca, matematika, dan sains. Bedasarkan laporan OECD, posisi pertama diraih oleh Singapura, kedua Jepang, ketiga Estonia, dan keempat Cina (Taipei).
Peringkat pendidikan dunia tersebut berhubungan dengan PISA (Program for International Student Assessment). PISA sendiri adalah program yang cukup disegani di seluruh dunia, dan kemungkinan besar politisi dan pembuat kebijakan untuk menilai perbedaan sistem pendidikan diberbagai Negara. Berdasarkan hasil studi PISA tahun 2015 Indonesia mendapatkan nilai membaca 397 , matematika 386 , dan sains 403 menunjukan bahwa Indonesia menduduki peringkat 52 dari 60 Negara yang ikut serta dalam kompetisi sains. Singapura masih menjadi peringkat tertinggi bahkan Negara tetangga lainnya Thailand masih berada di atas Indonesia dengan peringkat 44.

Peringkat dan rata-rata skor pencapaian siswa Indonesia tersebut tidak jauh berbeda dengan hasil tes dan survei dari data TIMSS (Trends In Mathematics and Science Study) pada tahun 2015 Indonesia mendapatkan skor matematika 397 Indonesia menduduki peringkat 45 dari 50 dan skor perolehan di bidang sains 397 Indonesia menduduki peringkat 45 dari 48 Negara yang ikut serta dalam kompetisi matematika dan sains. Singapura tetap menjadi peringkat tertinggi. Sejalan dengan kondisi peringkat pendidikan Indonesia dibandingkan Negara-negara lain di dunia, banyak faktor yang menentukan keberhasilan peserta didik.

Faktor-faktor yang menentukan keberhasilan peserta didik mulai dari sarana dan prasarana sekolah, kondisi ekonomi orang tua, lingkungan belajar, lingkungan keluarga, psikis dari peserta didik, dan peran pendidik (Kurniawan, 2016). Dari sekian banyak faktor yang mempengaruhi keberhasilan peserta didik yang paling berperan adalah pendidik dalam hal ini adalah guru. Saat ini tuntunan kurikulum 2013 guru sebagai mediator serta sebagai fasilitator dalam pembelajaran. Sebagai fasilitator, guru harus mampu menyediakan berbagai fasilitas belajar agar siswa dengan mudah bisa memperoleh informasi (Prasetyo, 2015).

Guru sebagai fasilitator dan mediator memerlukan media yang dapat digunakan dalam proses pembelajaran. 
Penggunaan media pembelajaran dalam proses pembelajaran juga dapat membantu siswa meningkatkan pemahaman, menyajikan data dengan menarik dan terpercaya, memudahkan penafsiran data, dan menyimpulkan informasi (Tania dan Fadiawati, 2015; Anwariningsih dan Ernawati, 2013). Fungsi media dalam proses pembelajaran tidak hanya sebagai media bantu guru melainkan media juga berperan dalam pembawa informasi atau data yang dibutuhkan oleh siswa (Benson, 2013). Media yang memuat gambar, video, audio, animasi, dan simulasi tentunya akan melibatkan lebih banyak indera yang dapat meningkatkan daya ingat siswa. Berbagai media yang digunakan serta metode dalam pembelajaran dapat mempengaruhi daya ingat siswa. Hal ini sesuai dengan penelitian (Davis dan Summers, 2014) yang menyebutkan bahwa kemampuan daya ingat dipengaruhi oleh pemilihan media, metode, dan bahan pembelajaran yang digunakan.

Salah satu media pembelajaran yang inovatif dan dapat meningkatkan daya ingat siswa terhadap materi pembelajaran IPA yaitu media pembelajaran menggunakan mind mapping. Windura (2010) menyatakan bahwa mind mapping adalah media pembelajaran yang sering digunakan diseluruh dunia. Media ini sudah membantu siswa di dunia untuk menggunakan kemampuan otaknya berpikir lebih tinggi dalam kegiatan belajar. Mind mapping adalah salah satu media yang menggunakan prinsip manajemen otak untuk membuka seluruh potensi dan kapasitas otak yang masih tersembunyi. $\mathrm{Hal}$ ini didukung oleh penelitian Nikhilkumar (2016) menunjukkan bahwa berdasarkan nilai rata-rata ujian, standar deviasi dan standar eror dari rata-rata hasil kuesioner didapat bahwa teknik pembelajaran dengan menggunakan media mind mapping lebih efektif digunakan daripada menggunakan teknik pengajaran tradisional. Penelitian lainnya adalah Lilisari et al. (2016) menyatakan bahwa peningkatan semua aspek berpikir kreatif siswa dengan menggunakan pembelajaran multimedia interaktif berbeda secara signifikan dengan pembelajaran powerpoint. Hasil penelitian Klentien dan Kamnungwut (2015) menyatakan bahwa perhatian siswa meningkat dan mereka lebih aktif dalam belajar menggunakan komputer karena media dapat menampung teks, gambar, video, animasi, audio, dan simulasi yang interaktif. Oleh karena itu, perlu dilakukan suatu penelitian pengembangan media pembelajaran IPA berbasis berbasis mind mapping.

Adapun tujuan penelitian ini adalah sebagai dasar untuk merancang media pembelajaran IPA berbasis mind mapping. Analisis kebutuhan dilakukan dengan studi pendahuluan meliputi studi literatur dan studi lapangan. Studi literatur dilakukan dengan mencermati kurikulum di sekolah dan konsep materi IPA di kelas VIII semester 2. Studi lapangan dilakukan dengan pengumpulan informasi terkait proses pembelajaran di kelas dan media yang digunakan.

\section{METODE}

Penelitian ini merupakan penelitian dan pengembangan atau sering disebut dengan Research and Development (R\&D). Model yang digunakan dalam penelitian ini adalah model pengembangan ADDIE yang terdiri dari lima tahapan yaitu (1) Analysis, (2) Design, (3) Development, Implementation, and (5) Evaluation. Pada penelitian pengembangan ini hanya dilakukan tiga tahap saja (Analysis, Design, dan Development) dikarenakan penelitian pengembangan ini hanya menilai validitas, keterbacaan, dan kepraktisan produk dan karena keterbatasan waktu dan biaya penelitian ini tidak sampai menilai keefektifannya.

Penelitian ini merupakan penelitian dengan model prosedural yang menunjukkan langkah-langkah dari proses pengembangan produk. Pengembangan produk dalam penelitian berbentuk media pembelajaran IPA berbasis mind mapping yang dikembangkan akan dinilai oleh ahli media, ahli bahasa, ahli isi, uji keterbacaan oleh siswa, dan uji kepraktisan oleh guru dan siswa. 
Data yang diperlukan dalam penelitian ini adalah data kualitatif dan kuantitatif. Data kualitatif didapat dari saran dan masukan ahli dan guru. Data kuantitatif didapat melalui hasil angket validasi, angket uji keterbacaan, dan angket uji kepraktisan. Teknik analisis data yang digunakan adalah teknik perhitungan rata-rata yang dikemukakan oleh Widoyoko (2009).

\section{HASIL DAN PEMBAHASAN}

Analisis kebutuhan sebagai dasar pengembangan media pembelajaran IPA berbasis mind mapping merupakan kegiatan pertama dilakukan oleh peneliti sebelum ke tahap design, dan development. Adapun studi pendahuluan yang dilakukan oleh peneliti yaitu studi literatur dan studi lapangan.

\section{Studi Literatur}

Studi literatur yang pertama dilakukan dengan menganalisis Kompetensi Inti (KI) dan Kompetensi Dasar (KD). Selain itu, juga dilakukan analisis konsep-konsep materi dalam hal ini adalah materi cahaya dan alat optik sebagai sampel materi yang dianalisis. Analisis kompetensi dasar dan kompetensi inti dilakukan dengan tujuan untuk mendapatkan indikator pembelajaran yang akan dicantumkan pada media pembelajaran IPA yang dikembangkan. Selanjutnya dari hasil analisis kompetensi inti dan kompetensi dasar ditetapkan indikator pembelajaran.

Studi literatur yang kedua dilakukan dengan menganalisis konsep-konsep materi, dalam hal ini adalah materi cahaya dan alat optik. Analisis konsep yang dilakukan adalah analisis yang dikembangkan oleh Herron (dalam Tsaparlis dan Kampourakis, 2000). Klasifikasi konsep menurut Herron mencakup delapan klasifikasi konsep yakni, (1) konsep konkret, (2) konsep abstrak, (3) konsep abstrak dengan contoh konkret, (4) konsep berdasarkan prinsip, (5) konsep yang menyatakan simbol, (6) konsep yang menyatakan nama proses, (7) konsep yang menyatakan sifat dan nama atribut, dan (8) konsep yang menyatakan ukuran atribut. Berdasarkan hasil analisis konsep pada topik cahaya dan alat optik berdasarkan klasifikasi konsep menurut Herron memiliki tiga dari delapan klasifikasi konsep yaitu (1) konsep konkret, (2) konsep abstrak, dan (3) konsep berdasarkan prinsip. Selengkapnya analisis konsep materi cahaya dan alat optik disajikan pada Tabel 1 sedangkan hasil analisis konsep materi cahaya dan alat optik disajikan pada Gambar 1.

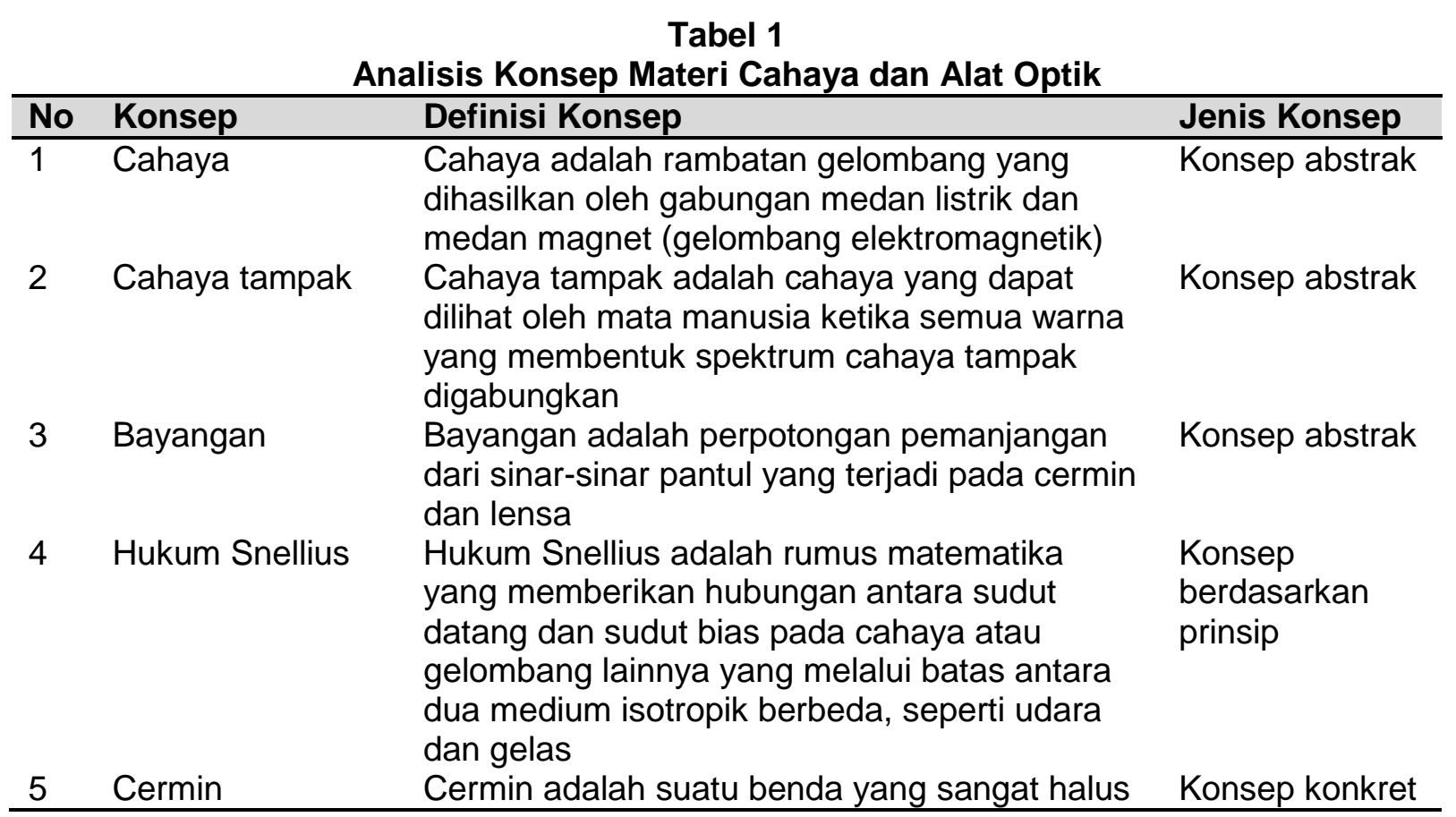




\begin{tabular}{|c|c|c|c|}
\hline No & Konsep & Definisi Konsep & Jenis Konsep \\
\hline & & dan mampu memantulkan cahaya & \\
\hline 6 & Cermin datar & $\begin{array}{l}\text { Cermin datar adalah cermin yang memiliki } \\
\text { permukaan datar dan dibelakang kaca dilapisi } \\
\text { logam tipis mengkilap sehingga tidak tembus } \\
\text { cahaya }\end{array}$ & Konsep konkret \\
\hline 7 & Cermin cekung & $\begin{array}{l}\text { Cermin cekung adalah cermin yang } \\
\text { permukaannya melengkung ke dalam, cermin } \\
\text { cekung bersifat mengumpulkan cahaya } \\
\text { (konvergen) }\end{array}$ & Konsep konkret \\
\hline 8 & Cermin cembung & $\begin{array}{l}\text { Cermin cembung adalah cermin yang } \\
\text { permukaannya melengkung ke luar, cermin } \\
\text { cembung bersifat menyebarkan cahaya } \\
\text { (divergen) }\end{array}$ & Konsep konkret \\
\hline 9 & Lensa & $\begin{array}{l}\text { Lensa adalah benda bening yang dibatasi oleh } \\
\text { dua permukaan berdasarkan bentuk } \\
\text { permukaannya }\end{array}$ & Konsep konkret \\
\hline 10 & Lensa cekung & $\begin{array}{l}\text { Lensa cekung adalah lensa yang bagian } \\
\text { tengahnya lebih tipis ketimbang bagian tepinya }\end{array}$ & Konsep konkret \\
\hline 11 & Lensa cembung & $\begin{array}{l}\text { Lensa cembung adalah sebuah lensa yang } \\
\text { bagian tengahnya memiliki ketebalan lebih } \\
\text { daripada bagian tepinya }\end{array}$ & Konsep konkret \\
\hline 12 & Mata & $\begin{array}{l}\text { Mata adalah organ penglihatan pada makhluk } \\
\text { hidup }\end{array}$ & Konsep konkret \\
\hline 13 & Rabun & $\begin{array}{l}\text { Rabun adalah gangguan pada penglihatan } \\
\text { yang menyebabkan objek terlihat kabur }\end{array}$ & Konsep abstrak \\
\hline 14 & $\begin{array}{l}\text { Rabun jauh } \\
\text { (miopi) }\end{array}$ & $\begin{array}{l}\text { Rabun jauh adalah cacat mata yang tidak } \\
\text { dapat melihat benda-benda yang jauh karena } \\
\text { lensa mata tidak dapat menjadi pipih sehingga } \\
\text { bayangan yang jauh terbentuk di depan retina }\end{array}$ & Konsep abstrak \\
\hline 15 & $\begin{array}{l}\text { Rabun dekat } \\
\text { (hipermetropi) }\end{array}$ & $\begin{array}{l}\text { Rabun dekat adalah cacat mata yang tidak } \\
\text { dapat melihat benda-benda yang dekat karena } \\
\text { lensa mata tidak dapat menjadi cembung } \\
\text { sehingga bayangan benda terbentuk di } \\
\text { belakang retina }\end{array}$ & Konsep abstrak \\
\hline 16 & $\begin{array}{l}\text { Mata tua } \\
\text { (presbiopi) }\end{array}$ & $\begin{array}{l}\text { Presbiopi adalah kondisi mata yang kehilangan } \\
\text { kemampuan fokus secara bertahap, untuk } \\
\text { melihat objek pada jarak dekat karena titik } \\
\text { dekat dan titik jauhnya telah bergeser }\end{array}$ & Konsep abstrak \\
\hline 17 & Buta warna & $\begin{array}{l}\text { Buta warna adalah kelainan pada mata yang } \\
\text { disebabkan ketidakmampuan sel-sel kerucut } \\
\text { mata untuk menangkap suatu warna tertentu }\end{array}$ & Konsep abstrak \\
\hline 18 & Astigmatisma & $\begin{array}{l}\text { Asigmatisma adalah gangguan pada mata } \\
\text { karena penyimpangan dalam pembentukan } \\
\text { bayangan pada lensa }\end{array}$ & Konsep abstrak \\
\hline 19 & Omatidium & $\begin{array}{l}\text { Omatidium adalah mata majemuk dari } \\
\text { anthropoda seperti serangga, krustasea, dan } \\
\text { kaki seribu }\end{array}$ & Konsep abstrak \\
\hline 20 & Lup & $\begin{array}{l}\text { Lup atau kaca pembesar adalah alat optik } \\
\text { berupa lensa cembung yang digunakan untuk } \\
\text { melihat benda-benda kecil agar terlihat lebih } \\
\text { besar }\end{array}$ & Konsep konkret \\
\hline
\end{tabular}




\begin{tabular}{llll}
\hline No & Konsep & Definisi Konsep & Jenis Konsep \\
\hline 21 & Teropong & $\begin{array}{l}\text { Teropong adalah sebuah alat optik yang } \\
\text { digunakan untuk melihat } \\
\text { benda-benda yang letaknya jauh agar tampak } \\
\text { lebih dekat dan jelas }\end{array}$ & Konsep konkret \\
& & $\begin{array}{l}\text { Mikroskop adalah alat optik yang berfungsi } \\
\text { untuk melihat benda-benda yang berukuran }\end{array}$ & Konsep konkret \\
& Mikroskop & $\begin{array}{l}\text { Sangat kecil } \\
\text { Kamera adalah alat optik yang mampu } \\
\text { merekam suatu kejadian dalam bentuk gambar }\end{array}$ & Konsep konkret \\
\hline
\end{tabular}

\section{Hasil Analisis Konsep Materi IPA Cahaya dan Alat Optik}

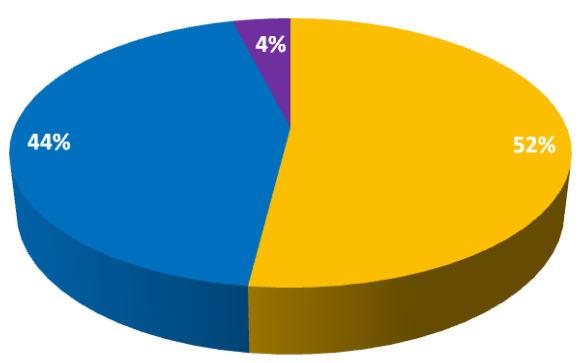

Konsep abstrak

Konsep konkret

Konsep berdasarkan prinsip

\section{Gambar 1. Diagram hasil analisis konsep materi IPA cahaya dan alat optik}

Studi lapangan

Studi lapangan dilakukan dengan menyebarkan kuesioner secara online dan terjun langsung ke beberapa sekolah SMP di Kabupaten Buleleng khususnya di Kecamatan Buleleng dan Kecamatan Sawan. Penyebaran kuesioner secara online menggunakan Google Form dipilih sebagai upaya untuk mempercepat penyebaran dengan jangkauan yang luas. Peneliti meminta bantuan kepada temanteman kelas untuk menyebar link ke beberapa sekolah di Kecamatan Buleleng dan Kecamatan Sawan, serta terjun langsung ke beberapa sekolah di Kecamatan Buleleng dan Kecamatan Sawan untuk menyebar link tersebut. Berikut hasil analisis kebutuhan guru dan hasil analisis kebutuhan siswa dapat dilihat pada Tabel 2 dan Tabel 3.

Tabel 2

Hasil Analisis Kebutuhan Guru

\begin{tabular}{cllc}
\hline No & Pernyataan & Respon Guru & Persentase (\%) \\
\hline 1 & Media yang biasanya digunakan & Buku & 57,9 \\
& dalam proses pembelajaran & LKS & 15,8 \\
& & Papan tulis & 15,8 \\
& & LKS, buku, dan papan tulis & 5,3 \\
& & PPT, buku, dan papan tulis & 5,2 \\
2 & Guru yang pernah menggunakan & Pernah & 100 \\
& $\begin{array}{l}\text { media ICT dalam proses } \\
\text { pembelajaran }\end{array}$ & Tidak pernah & - \\
3 & Media ICT yang digunakan dalam & Powerpoint & 78,9 \\
& proses pembelajaran & Media flash & - \\
& & Video & 21,1 \\
4 & Penggunaan multimedia Interaktif & Pernah & 57,9 \\
& dalam proses pembelajaran & Tidak pernah & 42,1 \\
\hline
\end{tabular}




\begin{tabular}{|c|c|c|c|}
\hline No & Pernyataan & Respon Guru & Persentase (\%) \\
\hline \multirow[t]{2}{*}{5} & Perlunya penggunaan multimedia & Perlu & 100 \\
\hline & $\begin{array}{l}\text { interaktif dalam proses } \\
\text { pembelajaran }\end{array}$ & Tidak perlu & - \\
\hline \multirow{4}{*}{6} & Cara guru memperoleh multimedia & Membuat sendiri & 5,6 \\
\hline & interaktif & Download dari internet & 88,8 \\
\hline & & Disediakan dari sekolah & - \\
\hline & & Tidak ada sarana & 5,6 \\
\hline \multirow[t]{2}{*}{7} & Guru yang pernah mendapatkan & Pernah & 10,5 \\
\hline & $\begin{array}{l}\text { pelatihan pembuatan multimedia } \\
\text { interaktif }\end{array}$ & Tidak pernah & 89,5 \\
\hline \multirow[t]{2}{*}{8} & Media pembelajaran berbasis mind & Menarik & 100 \\
\hline & $\begin{array}{l}\text { mapping merupakan media yang } \\
\text { menarik }\end{array}$ & Tidak menarik & - \\
\hline \multirow[t]{2}{*}{9} & Perlunya penggunaan media & Perlu & 100 \\
\hline & $\begin{array}{l}\text { pembelajaran berbasis mind } \\
\text { mapping digunakan dalam } \\
\text { menjelaskan materi IPA }\end{array}$ & Tidak perlu & - \\
\hline \multirow[t]{2}{*}{10} & Guru yang setuju menggunakan & Setuju & 100 \\
\hline & $\begin{array}{l}\text { media pembelajaran berbasis mind } \\
\text { mapping untuk menjelaskan materi } \\
\text { IPA }\end{array}$ & Tidak setuju & - \\
\hline
\end{tabular}

Tabel 3

Hasil Analisis Kebutuhan Siswa

\begin{tabular}{cllc}
\hline No & Pernyataan & Respon Siswa & Persentase (\%) \\
\hline 1 & Media yang digunakan oleh guru & Buku & 53,2 \\
& kepada siswa dalam proses & LKS & 26,8 \\
& pembelajaran & Papan tulis & 13,2 \\
& & LKS dan papan tulis & 0,6 \\
& Carta & 2,1 \\
& Buku dan LKS & 0,6 \\
& Buku, papan tulis, dan carta & 0,6 \\
& Laptop & 0,6 \\
& LCD & 0,6 \\
& Buku dan papan tulis & 1,1 \\
& Buku, LCD, LKS, papan tulis & 0,6 \\
& Siswa yang pernah diajarkan & Pernah & 90 \\
menggunakan media ICT dalam & Tidak pernah & 10 \\
proses pembelajaran & & \\
Sarana yang digunakan untuk & Powerpoint & 66,3 \\
menyajikan media ICT dalam & Media flash & 3,7 \\
proses pembelajaran & Video & 28,5 \\
& LCD & 0,5 \\
& Tidak ada sarana & 1 \\
\hline
\end{tabular}




\begin{tabular}{|c|c|c|c|}
\hline No & Pernyataan & Respon Siswa & Persentase (\%) \\
\hline 4 & $\begin{array}{l}\text { Siswa yang pernah diajarkan } \\
\text { menggunakan multimedia } \\
\text { interaktif dalam proses } \\
\text { pembelajaran }\end{array}$ & $\begin{array}{l}\text { Pernah } \\
\text { Tidak pernah }\end{array}$ & $\begin{array}{l}76,8 \\
23,2\end{array}$ \\
\hline 5 & $\begin{array}{l}\text { Penggunaan multimedia } \\
\text { interaktif membantu siswa dalam } \\
\text { memahami konsep }\end{array}$ & $\begin{array}{l}\text { Ya } \\
\text { Tidak }\end{array}$ & $\begin{array}{l}96,3 \\
3,7\end{array}$ \\
\hline 6 & $\begin{array}{l}\text { Perlunya penggunaan } \\
\text { multimedia interaktif dalam } \\
\text { proses pembelajaran }\end{array}$ & $\begin{array}{l}\text { Perlu } \\
\text { Tidak perlu }\end{array}$ & $\begin{array}{c}98,9 \\
1,1\end{array}$ \\
\hline 7 & $\begin{array}{l}\text { Siswa yang pernah diajarkan } \\
\text { menggunakan media } \\
\text { pembelajaran berbasis mind } \\
\text { mapping }\end{array}$ & $\begin{array}{l}\text { Pernah } \\
\text { Tidak pernah }\end{array}$ & $\begin{array}{l}33,2 \\
66,8\end{array}$ \\
\hline 8 & $\begin{array}{l}\text { Media pembelajaran berbasis } \\
\text { mind mapping merupakan media } \\
\text { yang menarik }\end{array}$ & $\begin{array}{l}\text { Menarik } \\
\text { Tidak menarik }\end{array}$ & $\begin{array}{c}95,3 \\
4,7\end{array}$ \\
\hline 9 & $\begin{array}{l}\text { Perlunya penggunaan media } \\
\text { pembelajaran berbas is mind } \\
\text { mapping digunakan dalam } \\
\text { menjelaskan materi IPA }\end{array}$ & $\begin{array}{l}\text { Perlu } \\
\text { Tidak perlu }\end{array}$ & $\begin{array}{l}97,4 \\
2,6\end{array}$ \\
\hline
\end{tabular}

Hasil analis kebutuhan guru dan siswa terhadap media yang dilakukan dengan penyebaran kuesioner kepada 19 orang guru IPA dan 190 orang siswa di Kecamatan Buleleng dan Kecamatan Sawan menunjukkan $100 \%$ guru menyatakan bahwa media pembelajaran IPA berbasis mind mapping itu menarik, $100 \%$ guru menginginkan perlunya dikembangkan media pembelajaran IPA berbasis mind mapping, dan $100 \%$ guru menyatakan setuju menggunakan media pembelajaran IPA berbasis mind mapping dalam menjelaskan konsep IPA. Dari hasil analisis kebutuhan siswa juga mendapatkan hasil yang tidak jauh berbeda dengan analisis kebutuhan guru, 95,3\% siswa menyatakan media pembelajaran IPA berbasis mind mapping itu menarik, dan $97,4 \%$ siswa menyatakan setuju menggunakan media pembelajaran IPA berbasis mind mapping pada kegiatan belajar di kelas.
Hal ini didukung dari hasil penelitian yang dilakukan oleh Ali (2009) bahwa produk yang dihasilkan berupa media pembelajaran sangat baik untuk mendukung belajar mandiri. Penelitian lainnya adalah Nikhilkumar (2016) menunjukkan bahwa berdasarkan nilai ratarata ujian, standar deviasi dan standar eror dari rata-rata hasil kuesioner didapat bahwa teknik pembelajaran dengan menggunakan

media mind mapping lebih efektif digunakan daripada menggunakan teknik pengajaran tradisional. Penelitian Lilisari et al. (2016) menyatakan bahwa peningkatan semua aspek berpikir kreatif siswa dengan menggunakan pembelajaran multimedia interaktif berbeda secara signifikan dengan pembelajaran powerpoint. Hasil penelitian Klentien dan Kamnungwut (2015) menyatakan bahwa perhatian siswa meningkat dan mereka lebih aktif dalam belajar menggunakan komputer karena media dapat menampung teks, gambar, video, animasi, audio, dan simulasi yang 
interaktif. Leow dan Neo (2014) menemukan dari hasil survei terhadap penggunaan multimedia didapat bahwa $87,1 \%$ dari siswa setuju bahwa video telah membantu mereka untuk mendapatkan informasi yang lebih realistis. $77,4 \%$ siswa setuju bahwa penggunaan media dapat memperdalam pemahaman mereka. Hasil tersebut menunjukkan bahwa unsur-unsur pada multimedia seperti video atau gerak grafis dapat memberikan informasi lebih rinci. Mengintegrasikan berbagai media ke dalam pembelajaran sangat penting untuk meningkatkan hasil belajar siswa serta meningkatkan keterampilan mengajar guru itu sendiri (Ghavifekr et al., 2014) Penggunaan komputer yang merujuk pada multimedia interaktif dalam pembelajaran secara langsung sangat penting dalam meningkatkan kualitas, aksesbilitas, dan efesiensi biaya untuk mencapai tujuan yang diharapkan (Ghavifekr dan Rosdy, 2015). Karena kekuatan kolaborasi dan komunikasi antara siswa dengan guru adalah dua faktor dasar dalam motivasi belajar (Vero dan Puka, 2017). Dari hasil studi literatur, studi lapangan, dan hasil penelitian yang dilakukan memang perlu dikembangkan media pembelajaran IPA berbasis mind mapping.

\section{SIMPULAN DAN SARAN}

Berdasarkan hasil analisis kebutuhan sebagai dasar pengembangan media pembelajaran IPA berbasis mind mapping dapat disimpulkan bahwa hasil analisis terhadap konsep materi IPA kelas VIII semester 2 pada topik Cahaya dan Alat Optik berdasarkan klasifikasi konsep menurut Herron memiliki tiga dari delapan klasifikasi konsep yaitu (1) konsep konkret $52 \%$, (2) konsep abstrak $44 \%$, dan (3) konsep berdasarkan prinsip 4\%. Dan hasil analisis kebutuhan guru dan siswa dari 19 orang guru IPA dan 190 orang siswa di Kabupaten Buleleng khususnya di Kecamatan Buleleng dan Kecamatan Sawan menunjukkan $100 \%$ guru menginginkan perlunya dikembangkan media pembelajaran IPA berbasis mind mapping dan 97,4\% siswa menyatakan setuju menggunakan media pembelajaran IPA berbasis mind mapping pada kegiatan belajar di kelas. Dapat disimpulkan dari hasil studi literatur dan studi lapangan bahwa memang perlu dikembangkan media pembelajaran IPA berbasis mind mapping.

Sebagai tindak lanjut dari hasil penelitian ini, maka dikemukakan saran yaitu analisis konsep hendaknya dianalisis pada semua materi IPA di kelas VIII semester 2. Hal ini dilakukan untuk mengetahui konsep-konsep abstrak yang perlu dikaji lebih lanjut sehingga konsepkonsep abstrak tersebut dapat disajikan dengan menggunakan media pembelajaran sebagai upaya untuk memudahkan dalam menguasai materi. Analisis kebutuhan terhadap guru dan siswa hendaknya dilakukan di sekolah di Kabupaten Buleleng sehingga dari data yang didapatkan kemudian dapat dikembangkannya media pembelajaran IPA berbasis mind mapping yang disesuikan pada kondisi sekolah dan karakteristik siswa yang berbeda.

\section{DAFTAR PUSTAKA}

Ali, M. 2009. "Pengembangan Media Pembelajaran Interaktif Mata Kuliah Medan Elektromagnetik". Jurnal Edukasi Elektro Vol. 5, No 1, Maret 2009, hlm. 11-18.

Anwariningsih, S. H. 2013. Development of interactive Media for ICT Learning at Elementary School Based on Student Self Learning, 7(154), 121128.

Benson, A., \& Odera, F. 2013. Selection and use of Media in Teaching Kiswahili Language in Secondary School in Kenya. International Journal of Information and Communication Technology, 3(1), 12-18.

Davis, B., \& Summers, M. 2015. Applying Dale's Cone of Experience to increase learning and retention: $A$ study of student learning in a foundational leadership course. QScience Proceedings, 2015(4),6.

Ghavifekr, S., Ahmad, Z. A. R. M. F. A. Ghani, Ran, N. Y. meixi, Y., \& Tengyue, Z. 2014. ICT Integration In Education: Incorporation for Teaching \& Learning Improvement. 
Malaysian Online Journal of Education Technology, 2(2), 24-54.

Ghavifekr, S., Athirah, W., \& Rosdy, W. 2015. Teaching and Learning with Technology: Effectiveness of ICT Integration in School. International Journal of Research in Education and Scince (IJRES) International Journal of Research in Education and Science E, 1(2), 175-191.

Hamalik, O. 2013. Kurikulum dan Pembelajaran. Jakarta: Bumi Aksara

IEA's Trends in International Mathematics and Science Study. 2016. Match Student Achivement Infographic Grade 4. TIMSS 2015.

Klentien, U., \& Kamnungwut, W. 2015. The Impact of Using Elektronic Media in English Teaching for Elementary and

Secondary Students in Thailand. International Journal of information and Education Technology, 5(8), 582-586.

Leow, F., \& Neo, M. 2014. Interactive Multimedia Learning: Innovating Classromm Education in a Malaysia University. TOJET: The Turkish Online Journal of Educational Technology, 13(2). INTI International University: Malaysia.

Lilisari, S. S., \& Hana, M, N. 2016. Students Creative Thinking Enhancement Using Interactive Multimedia of Redox Reaction Creative Thinking Enhancement, 3034.

Nikhilkumar, D. P. 2016. Effectiveness of Teaching through Mind Mapping Technique. The International Journal of Indian Psychology, 3 (3). Pasific Academy of Higher Education and Research University: Udaipur, Rajasthan.

OECD. 2015. PISA 2015: Results in focus. Pisa 2015, (67), 16.

Prasetyo, Z. K. 2015. "Research and Development: Pengembangan Berbasis Penelitian". Makalah disajikan dalam kuliah umum pada Dosen Pembimbing Tesis dan
Mahasiswa Magister Pendidikan Sains Program Pascasarjana Universitas Negeri Surakarta, 14 Juni 2012.

Rosyada, D. 2004. Paradigma Pendidikan Demokratis. Jakarta: Prenada Media

Rusdi. 2018. Penelitian Desain dan pengembangan Kependidikan: Konsep, Prosedur dan Sintesis Pengetahuan Baru. Depok: Raja Grafindo Persada.

Tania, L., \& Fadiawati, N. 2015. The Development of interactive- book based chemistry representations referred to the curriculum of 2013. Jurnal pendidikan IPA Indonesia, 4(2), 164-169.

Tsaparlis, G., \& Kampourakis, C. 2000. An Integrated Physical-Science (Physics AndChemistry) Indtroduction For Lower-Secondary Level (Grade 7) Chemical Education in Europe: Curricula and Policies, 1(2), 281-294.

Undang-undang No. 20 Tahun 2003 tentang Sistem Pendidikan Nasional, $2003 . \quad$ Jakarta.

Vero, E., \& Puka, E. 2017. The Importance of Motivation in an Educational Environment L'importanza della motivazione in un ambiente educativo. Formazione \& insegnamento $X V$, 57-66.

Widoyoko, E. P. 2009. Evaluasi Panduan Pembelajaran: Panduan Praktis Bagi Pendidikan dan Calon Pendidiki. Yogyakarta: Pustaka Pelajar.

Widura, S. 2010. Mind Map Langkah Demi Langkah. Yogyakarta: Gramedia. 